\title{
PR Interval
}

National Cancer Institute

\section{Source}

National Cancer Institute. PR Interval. NCI Thesaurus. Code C83502.

The time interval between the start of the P wave and the beginning of the QRS complex in the cardiac cycle. 